\title{
Mortality among drowning rescuers in China, 2013: a review of 225 rescue incidents from the press
}

\author{
Yinchao Zhu ${ }^{1^{*+}}$, Xia Jiang ${ }^{2 \dagger}$, Hui Li ${ }^{1}$, Fudong $\mathrm{Li}^{3}$ and Jieping Chen ${ }^{1}$
}

\begin{abstract}
Background: Drowning is common worldwide. Rescue efforts attempted by untrained bystanders often lead to the death of the primary drowning victim (PDV), the rescuer or both. Our study aimed to inform prevention by identifying risk factors in rescuer drowning.

Methods: Data on drowning rescue incidents reported online in mainland China, 2013, were reviewed. Information on the drowning incidents, PDVs and rescuers were retrieved for analysis.

Results: A total of 225 rescue incidents were identified, of which 14 were victim-rescuer drowning incidents (VRDIs) (6.2 \%). A person-to-person rescue by swimming to PDVs was the most commonly used method (58.9\%). Resuscitation was given immediately to $35.5 \%$ of PDVs after rescue. The mortality rate of the rescuers (13.3\%) was similar to that of the PDVs (11.5\%) $\left(x^{2}=0.5, p=0.49\right)$. Being an adult $(\mathrm{OR}=0.2,95 \% \mathrm{Cl}: 0.1-0.5)$ and other than the first rescuer (OR $=0.4$, $95 \%$ Cl: 0.2-0.9) decreased the risk of rescuers drowning.

Conclusions: Most of the currently employed life-saving methods are dangerous and even potentially life threatening. The idea of "rescuers' safety first" should be embraced, especially with teenage and child rescuers, who should never be encouraged to rescue others without first guaranteeing their own safety. Promotion of basic rescue skills should be implemented in the general public.
\end{abstract}

Keywords: Drowning, Rescue, Risk factors, Primary drowning victims, Victim-rescuer drowning incidents, Safety, China

\section{Background}

Drowning has been defined as the process of experiencing respiratory impairment from submersion or immersion in liquid [1], with outcomes classified as death, morbidity, or no morbidity [2]. Some survivors are left with permanent neurologic impairment $[3,4]$ that inflicts a heavy burden on both their family and society [5]. Moreover, drowning is a major public health concern and a leading cause of unintentional injury deaths globally [6-8]. The worldwide estimate of 388,000 drowning deaths in 2004 [8] is believed to be under-approximated by $40-50 \%$ [9]. Because of preventive measures, death rates from drowning among

\footnotetext{
* Correspondence: zhuyc@nbcdc.org.cn

${ }^{\dagger}$ Equal contributors

'Institute of Non-Communicable Disease Control and Prevention, Ningbo Municipal Center for Disease Control and Prevention, No. 237, Yongfeng Road, Haishu District, Ningbo, Zhejiang Province 315010, People's Republic of China

Full list of author information is available at the end of the article
}

high-income countries have declined over recent decades $[6,10,11]$. However, rates remain high among low- and middle-income countries [7, 8, 12, 13], and China ranks highest in the number of drowning deaths worldwide [8].

Drowning cases where bystanders were on the scene and made an effort to rescue (usually because of a sense of duty, supererogation and altruism [14]) often made a crucial difference in the victims' survival [15]. Among the few studies focused on rescue-related drowning incidents in which the rescuers have drowned [14-17], the proportion of PDVs who survived has varied by population (43.9 \% in Turkey and $93 \%$ in Australia) [16, 17]. We actually do not know how many rescuers survived their rescue attempts. We only know those who lost their lives, but not an overall total number (rescuers who died plus rescuers who survived, as the baseline denominator); therefore, we cannot calculate the risk of drowning while attempting a rescue $[14,16,17]$.

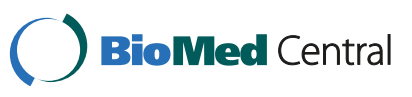


Moreover, given all the permutations of internal and external elements the rescuers would encounter, as well as the shortage of time to plan for a safe approach, untrained rescuers may not only fail to rescue victims, but may subject themselves to so-called victim-instead-ofrescuer syndrome [16] and cause multiple drowning incidents [17].

Therefore, the goal of this research was to inform development of preventive strategies by identifying the risk factors for drowning rescuers. The goal was addressed by examining the cases of drowning rescues reported online in the mainland Chinese media in 2013.

\section{Methods}

This study was approved by the ethical committee of Ningbo Municipal Center for Disease Control and Prevention. The data collection process is shown in a flowchart (Fig. 1). 'Baidu' ('百度' in Chinese), the world's largest Chinese language search engine, was used to search for Chinese news reports. All cases were retrieved from online news reports with at least two of the following keywords tagged: 'drowning,' near-drowning,' 'fall into water,' 'rescue, 'life-saving', and 'sacrifice' ('淹死, ‘溺水, ‘落 水, ‘救人, ‘救命, '牺牲' in Chinese). We covered both unintentional and intentional drowning cases. All the cases were from websites of national or regional newspapers, and police and fire departments. Owing to the lack of full information from a single report, related reports identified as having the same name of victims or rescuers or a similar news title were also searched further, with the aim of collecting the most complete information for each event.
The following variables were constructed: (1) Incidents: province, date, time, drowning locations; (2) PDVs: demographic characteristics, cause of drowning, whether reported by the news as being a swimmer, survival status, symptoms (for survivors) and whether first aid was provided; (3) Rescuers: demographic characteristics, whether reported by the news as being a swimmer, rescue rank (whether the rescuer was the first, second, or some subsequent person to attempt rescue), whether the rescuers called for others' help and whether they undressed before the rescue, rescue measures, number of drowning victims in need, whether difficulties were experienced and the nature of such difficulties, and survival status. After excluding 25 cases that were missing more than half of the variables, we eventually obtained 91 cases of incidents, 99 PDVs, and 64 rescuers with virtually complete information, constituting $40.4 \%, 36.5 \%$ and $15.4 \%$ of the total number of incidents (225), PDVs (271) and rescuers (416), respectively.

\section{Terms and definitions}

The details on terms and their definitions are provided in Table 1. In addition, season was defined on the basis of Chinese meteorological phenomena (spring: Mar, Apr and May; summer: Jun, Jul and Aug; autumn: Sep, Oct and Nov; winter: Dec, Jan and Feb). Time was divided into four sections (Night: 0:00-6:00; Morning: 6:0012:00; Afternoon: 12:00-18:00; Evening: 18:00-24:00). The target population was classified into two groups (children/teenagers: $<18$; adults: $\geq 18$ ). All variables related to the rescue incidents and rescuers were defined by the authors of the present study.

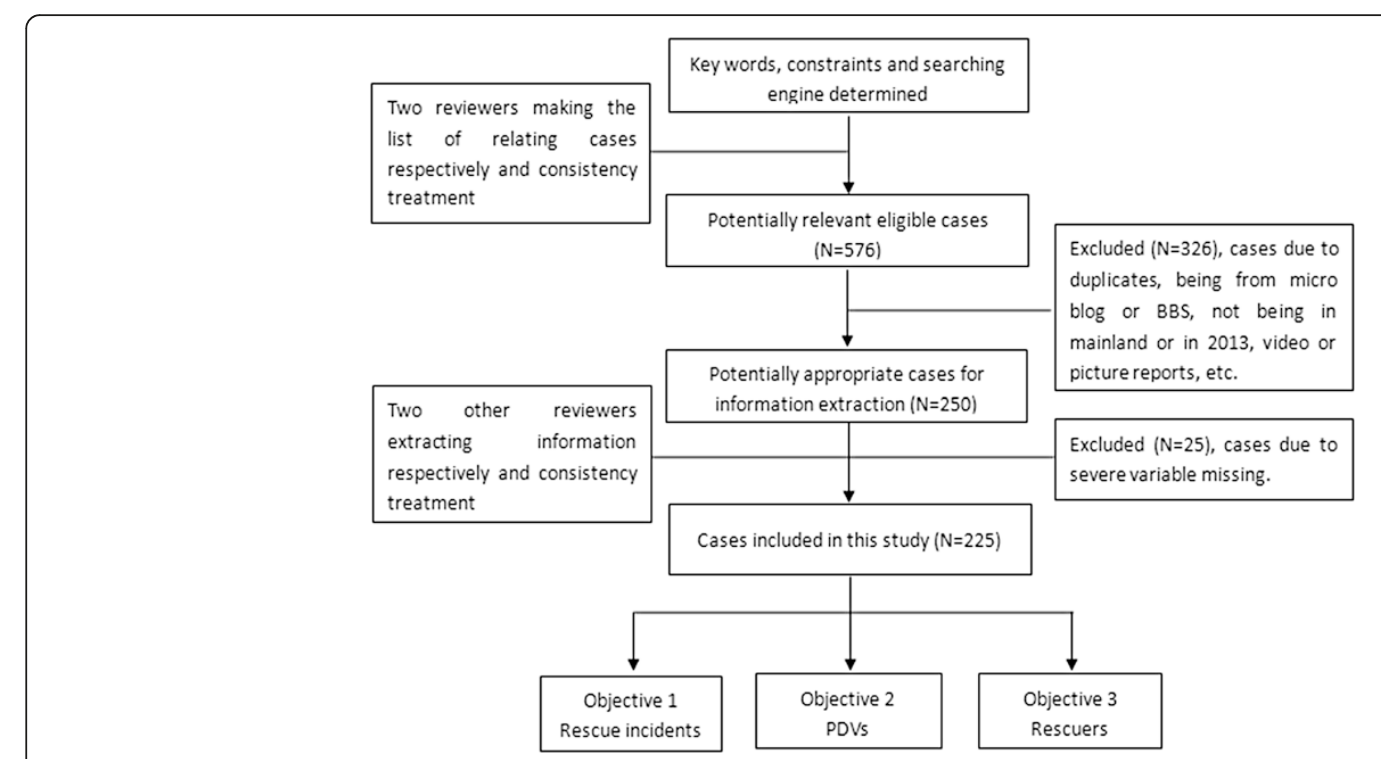

Fig. 1 Flow chart of data collection process. The detailed peocess of data collection and quality control was showed 
Table 1 List of terms and definitions

\begin{tabular}{|c|c|c|}
\hline Terms & Abbreviations & Definition \\
\hline Primary drowning victim & PDV & PDV referred to the victim who fell into liquid initially and may result in death from drowning [17]. \\
\hline Rescue & & $\begin{array}{l}\text { Rescue meant rescuers managed to save the original PDV and any rescuers who became PDVs } \\
\text { directly no matter they were dead or survival finally. }\end{array}$ \\
\hline $\begin{array}{l}\text { Victim-rescuer drowning } \\
\text { incident }\end{array}$ & VRDI & VRDI meant rescuers became dead as well as PDV in the rescue incident. \\
\hline Survival & & $\begin{array}{l}\text { Survival was defined as a PDV and/or rescuer who had vital signs or regaining them after resuscitation } \\
\text { as judged by reviewers based on the media reports. }\end{array}$ \\
\hline Successful rescue & & Successful rescue meant rescuers helped the drowning victim to extricate from liquid. \\
\hline Rescue rank & & $\begin{array}{l}\text { Rescue Rank is the order for each rescuer who undertakes a rescue action, a rank of ' } 1 \text { ' would be given } \\
\text { to the first person who carried out the rescue, ' } 2 \text { 'for the next, and so on. If several rescuers implemented } \\
\text { simultaneously, the same rank would be given to each. }\end{array}$ \\
\hline
\end{tabular}

\section{Data analysis}

All data were analyzed in SAS V9.20 (SAS Institute, Inc.; Cary, North Carolina, USA). The Pearson $\chi^{2}$ test and Kruskal-Wallis rank-sum test with two independent samples were used for categorical and continuous outcomes, respectively. The data for number of rescuers and rescuer deaths were clustered and showed negative binomial distributions. Therefore, a two-level unconditional logistic regression model was adopted for the multivariate analysis. A $p$-value of less than 0.05 was set as the level of significance in this study.

\section{Results}

\section{Rescue incidents}

In total, 225 rescue-related incidents were identified from January 1 to December 31, 2013, including 271 PDVs and 416 rescuers, from 32 provinces, autonomous regions or municipalities in mainland China. The three provinces with the greatest share of incidents were Zhejiang (33, $14.7 \%)$, Jiangsu $(25,11.1 \%)$ and Sichuan (20, $8.9 \%)$. Incidents varied by seasons, with a larger proportion identified in spring, summer and autumn $(21.8 \%, 37.3 \%$ and $30.2 \%)$ than in winter (10.7\%). Almost all cases occurred during daytime $(22.5 \%$ in the morning and $55.0 \%$ in the afternoon), with a small proportion occurring during the night $(1.5 \%)$ or evening (21.0\%).

Twenty eight $(12.4 \%)$ rescue incidents had more than one PDV, with a maximum of five. In just over half (53.0\%) of cases, PDVs were adults only; in $44.2 \%$ they were children only and in $2.8 \%$, both adult and child PDVs were identified. In $54.2 \%$ of cases there was only one rescuer, in $26.7 \%$ there were two, in $9.3 \%$ there were three, and in $9.8 \%$ there were more than three, with a maximum of 12 . The average number of rescuers in a rescue incident surpassed that of PDVs (1.9 versus $1.2, p<0.01)$. There were 28 incidents $(12.4 \%)$ with at least one PDV mortality, and 40 incidents $(17.8 \%)$ with at least one rescuer mortality; together these contributed to 14 VRDIs (6.2\%). Furthermore, there were 26 cases
(11.6\%) with no PDV mortality but more than one rescuer mortality, 14 cases $(6.2 \%)$ with no rescuer mortality but more than one PDV mortality, and 171 incidents (76.0 \%) with no mortality.

\section{Primary drowning victims}

The successful rescue rate for PDVs was $88.5 \%$ (239 of a total of 270 PDVs) (Table 2); $55.4 \%$ were males, $54.2 \%$ were adults and $91.9 \%$ were non-swimmers (Table 2). The majority (96.3\%) of the drowning incidents occurred in fresh water. Ponds were the most common drowning places for children but not adults (18.6\% versus $\left.2.8 \%, \chi^{2}=20.3, \mathrm{p}<0.01\right)$. Falling was the first leading cause of drowning, accounting for $64.6 \%$ of incidents (Table 3). After being rescued, $56.8 \%$ of PDVs survived with no obvious symptoms; $27.2 \%$ were in a coma; $9.6 \%$ experienced apnea or dyspnea and $2.6 \%$ went into cardiac arrest. Among all PDVs, $35.5 \%$ were given pre-hospital resuscitation on the scene, and $39.9 \%$ were sent to hospitals without delay (data not shown).

\section{Rescuers}

The average number of drowning people in need of rescue (including the original PDV and any rescuers who became PDVs) was $1.5 \pm 1.0$ per incident. Despite a relatively high successful rescue rate among PDVs, no significant difference in mortality rate was found between rescuers (13.3\%) and original PDVs (11.5\%) (Table 2). Compared with PDVs, rescuers were more likely to be males $(91.0 \%)$, adults $(81.6 \%)$ and swimmers (79.9\%) (Table 2 ). Significantly fewer (38.6\% versus $86.9 \%$ ) child than adult rescuers were swimmers $\left(\chi^{2}=55.4, \mathrm{p}<0.01\right)$.

For rescuers, $12.1 \%$ asked for assistance from others and $26.8 \%$ removed either their shoes or clothing before the rescue. Most of the rescuers (80.1\%) chose to enter the water in the attempt to save the victims. Furthermore, 58.9 \% of rescuers swam to PDVs to undertake rescue directly. Owing to lack of swimming skills, exhaustion or difficult water conditions, 97 rescuers 
Table 2 Basic information on PDVs and rescuers in 225 rescue incidents, $\mathrm{n}(\%)$

\begin{tabular}{lllll}
\hline & PDVs & Rescuers & Chi-Square & $p$-value \\
\hline Total & 271 & 416 & & \\
Average number of & 1.2 & 1.9 & 59.9 & $<0.01$ \\
persons per incident & & & & \\
Gender & & & & \\
$\quad$ Male & $139(55.4)$ & $373(91.0)$ & 113.0 & $<0.01$ \\
Female & $112(44.6)$ & $37(9.0)$ & & \\
Total & 251 & 410 & & \\
Being an adult & & & \\
$\quad$ Yes & $141(54.2)$ & $337(81.6)$ & 58.1 & \\
No & $119(45.8)$ & $76(18.4)$ & & \\
Total & 260 & 413 & & \\
Being a swimmer & & & \\
Yes & $18(8.1)$ & $251(79.9)$ & 269.4 & \\
No & $205(91.9)$ & $63(20.1)$ & & \\
Total & 223 & 314 & & \\
Being a survivor & & & \\
Yes & $239(88.5)$ & $359(86.7)$ & 0.5 & \\
No & $31(11.5)$ & $55(13.3)$ & & \\
Total & 270 & 414 & & \\
\hline
\end{tabular}

The inconsistencies among the total frequencies of certain variables were caused by missing data

Table 3 Drowning cause and locations among 271 PDVs

\begin{tabular}{lll}
\hline & N & (\%) \\
\hline Locations of drowning & 176 & 65.7 \\
River/creek/stream & 31 & 11.6 \\
Lake & 26 & 9.7 \\
Pond & 14 & 5.2 \\
Ditch & 11 & 4.1 \\
Other (e.g., reservoir, well, swimming pool) & 10 & 3.7 \\
Sea/beach & 268 & 100.0 \\
Total & & \\
Cause of drowning & 142 & 64.6 \\
Falling from the bank & 30 & 13.6 \\
Traffic accident & 18 & 8.2 \\
Suicide & 11 & 5.0 \\
Other (e.g., swimming accident, flood, electric shock) & 10 & 4.6 \\
Row/raft & 9 & 4.1 \\
Sliding off in the water close to the shore & 220 & 100.0 \\
Total & &
\end{tabular}

The inconsistencies among the total frequencies of certain variables were caused by missing data
(23.5\%) encountered hazardous situations and experienced difficulties; of these, $57.3 \%$ died (Table 4).

The average rescue rank was $1.5 \pm 0.8$. The rescue rank for those who died was significantly lower than for those who survived (1.3 versus $1.5, p<0.01$ ). A significant association between location and likelihood of rescuer survival was identified, wherein rescuers in a lake were less likely to drown compared with those in ponds and other locations. Adult and swimmer rescuers were more likely to survive than children and non-swimmers. Rescuers who used only their hands to pull victims through the water to shore had the lowest survival rate, and those who performed rescues in the context of a boating situation (pulling the victim by standing on the boat) the highest (Table 5).

After adjustment for confounding factors in a twolevel logistic regression, only two factors remained significant as predictors of rescuer drowning. Being an adult rescuer was associated with an $83.6 \%$ decrease in the risk of drowning (AOR $=0.2,95 \% \mathrm{CI}: 0.1-0.5, p<0.01$ ), while increasing rescue rank predicted a $55.7 \%$ decrease in risk $(\mathrm{AOR}=0.4,95 \%$ CI: 0.2-0.9, $p<0.05)$ (Table 6).

\section{Discussion}

As a populous developing country, China not only ranks highest in the number of drowning deaths worldwide [8] but also has a high drowning mortality rate of 4.4 per 100,000 people [13]. Among drowning deaths in China, some would certainly be cases of victim-instead-of-rescuer syndrome, although the proportion is unclear as there is a lack of relevant research. Our data suggest an average of $0.2(55 / 225)$ rescuer deaths per rescue

Table 4 Rescue methods and causes of experiencing difficulties among 416 rescuers

\begin{tabular}{lll}
\hline & $\mathrm{N}$ & (\%) \\
\hline Rescue methods & 245 & 58.9 \\
Swimming to the victim & 88 & 21.2 \\
Pulling in water close to the shore & 45 & 10.8 \\
Giving an extension(e.g., pole, lifeline) & 34 & 8.2 \\
Pulling on shore & 19 & 4.6 \\
Pulling by standing on the boat & 18 & 4.3 \\
Throw the floats & 416 & \\
Total & & \\
Cause of experiencing difficulties & 36 & 37.1 \\
Being a non-swimmer & 30 & 30.9 \\
Exhaustion & 28 & 28.9 \\
Bad water conditions (e.g., torrent, turbulence) & 13 & 13.4 \\
Steep edge & 7 & 7.2 \\
Other (e.g., cold, electric shock) & 97 & \\
Total &
\end{tabular}


Table 5 Factors in rescuer survival and mortality, n (\%)

\begin{tabular}{|c|c|c|c|c|}
\hline & Survival & Dead & Chi-Square & $p$-value \\
\hline Total & 359 & 55 & & \\
\hline Average rescue rank ${ }^{a}$ & 1.5 & 1.3 & 6.7 & $<0.01$ \\
\hline $\begin{array}{l}\text { Average number of drowning } \\
\text { men in need of rescue }\end{array}$ & 1.5 & 1.3 & 10246.5 & 0.08 \\
\hline \multicolumn{5}{|l|}{ Season } \\
\hline Spring & $78(21.7)$ & 13(23.6) & 2.1 & 0.55 \\
\hline Summer & $128(35.7)$ & $24(43.6)$ & & \\
\hline Autumn & $116(32.3)$ & 13(23.6) & & \\
\hline Winter & $37(10.3)$ & $5(90.1)$ & & \\
\hline \multicolumn{5}{|l|}{ Time } \\
\hline Night & $4(1.2)$ & $0(0.0)$ & 1.5 & 0.69 \\
\hline Morning & $73(22.3)$ & $14(27.5)$ & & \\
\hline Afternoon & 193(59.0) & $30(58.8)$ & & \\
\hline Evening & $57(17.4)$ & $7(13.7)$ & & \\
\hline \multicolumn{5}{|l|}{ Location } \\
\hline River/creek/stream & $228(64.4)$ & $30(54.6)$ & 25.1 & $<0.01$ \\
\hline Lake & $47(13.3)$ & $2(3.6)$ & & \\
\hline Pond & $29(8.2)$ & $12(21.8)$ & & \\
\hline Ditch & $17(4.8)$ & $1(1.8)$ & & \\
\hline $\begin{array}{l}\text { Other (e.g., reservoir, well, } \\
\text { swimming pool) }\end{array}$ & $17(4.8)$ & $9(16.4)$ & & \\
\hline Sea/beach & $16(4.5)$ & $1(1.8)$ & & \\
\hline \multicolumn{5}{|l|}{ Gender } \\
\hline Male & $321(86.5)$ & $50(13.5)$ & 0.1 & 0.07 \\
\hline Female & $36(97.3)$ & $1(2.7)$ & & \\
\hline \multicolumn{5}{|l|}{ Being an adult } \\
\hline Yes & $307(91.4)$ & $29(8.6)$ & 35.9 & $<0.01$ \\
\hline No & $49(65.3)$ & $26(34.7)$ & & \\
\hline \multicolumn{5}{|l|}{ Being a swimmer } \\
\hline Yes & 228(91.2) & $22(8.8)$ & 22.8 & $<0.01$ \\
\hline No & $43(68.3)$ & 20(31.8) & & \\
\hline
\end{tabular}

Calling for others' help when rescuing

$\begin{array}{llll}\text { Yes } & 45(91.8) & 4(8.2) & 0.9 \\ \text { No } & 303(85.8) & 50(14.2) & \\ \text { Undressing when rescuing } & & & \\ \text { Yes } & 82(89.1) & 10(10.9) & 0.1 \\ \text { No } & 221(88.8) & 28(11.2) & \end{array}$

Rescue methods

Pulling on shore

\begin{tabular}{|c|c|c|}
\hline Yes & $32(94.1)$ & $2(5.9)$ \\
\hline No & $327(86.1)$ & $53(13.9)$ \\
\hline
\end{tabular}

Pulling in water close to the shore

\begin{tabular}{|c|c|c|}
\hline Yes & 64(73.6) & $23(26.4) \quad 1$ \\
\hline No & $295(90.2)$ & \\
\hline
\end{tabular}

Table 5 Factors in rescuer survival and mortality, n (\%) (Continued)

\begin{tabular}{|c|c|c|c|c|}
\hline \multicolumn{5}{|c|}{ Swimming } \\
\hline Yes & 215(88.1) & 29(11.9) & \multirow[t]{2}{*}{1.0} & \multirow[t]{2}{*}{0.31} \\
\hline No & 144(84.7) & $26(15.3)$ & & \\
\hline \multicolumn{5}{|c|}{ Throwing the floats } \\
\hline Yes & $17(94.4)$ & 1(5.6) & \multirow[t]{2}{*}{0.2} & \multirow[t]{2}{*}{0.49} \\
\hline No & $342(86.4)$ & 54(13.6) & & \\
\hline \multicolumn{5}{|c|}{ Giving an extension } \\
\hline Yes & $44(97.8)$ & $1(2.2)$ & \multirow[t]{2}{*}{5.4} & \multirow[t]{2}{*}{0.02} \\
\hline No & $315(85.4)$ & $54(14.6)$ & & \\
\hline \multicolumn{5}{|c|}{ Pulling by standing on the boat } \\
\hline Yes & 19(100.0) & $0(0.0)$ & \multirow[t]{2}{*}{0.1} & \multirow[t]{2}{*}{0.09} \\
\hline No & $339(86.0)$ & $55(14.0)$ & & \\
\hline
\end{tabular}

${ }^{a}$ indicates two independent samples Kruskal-Wallis rank sum test was used for analysis. All other analyses were Pearson $x^{2}$ tests

incident, and a mortality rate of rescuers statistically indistinguishable from that of PDVs, which indicates that drowning rescue is a high-risk activity $[18,19]$. Ensuring awareness of rescuers' safety first [20] might help reduce the mortality.

Unfortunately, but perhaps unsurprisingly, children constituted a large proportion of drowning victims for both PDVs $[6,21]$ and rescuers. The underlying reasons could be diverse. On one hand, children usually have limited competence at flexible cognitive control, exhibit a low risk perception and an overestimation of their swimming ability, all of which could lead to increased immature decision-making and risk-taking behaviors [22-24]. This speculation may be supported by the fact that more non-swimmers were found among the children than among the adult rescuers in our current study. On the other hand, the ethics that children have learned could also drive them to take altruistic actions [14, 25].

Table 6 Two-level logistic regression analysis for risk factors associated with rescuers' drowning

\begin{tabular}{llll}
\hline & $\begin{array}{l}\text { Regression } \\
\text { coefficient } \beta\end{array}$ & $p$-value & $\begin{array}{l}\text { Odds Ratio } \\
(95 \% \mathrm{Cl})\end{array}$ \\
\hline Rescue rank & -0.8 & $<0.05$ & $0.4(0.2-0.9)$ \\
Being an adult & -1.8 & $<0.01$ & $0.2(0.1-0.5)$ \\
$\begin{array}{l}\text { Being a swimmer } \\
\text { Pulling in water close to } \\
\text { the shore }\end{array}$ & 1.3 & 0.06 & $3.6(0.9-14.4)$ \\
$\begin{array}{l}\text { Giving an extension } \\
\text { Location }\end{array}$ & -1.7 & 0.82 & $1.2(0.3-4.9)$ \\
Lake & & 0.24 & $0.2(0.1-3.1)$ \\
Pond & -0.9 & 0.37 & $0.4(0.1-2.8)$ \\
$\begin{array}{l}\text { Other (e.g., reservoir, well, } \\
\text { swimming pool) }\end{array}$ & 1.3 & 0.08 & $3.7(0.9-16.3)$ \\
\hline
\end{tabular}


Therefore, the appropriateness of firmly discouraging children who cannot swim from rescuing should be brought into public awareness.

Local geographic conditions accounted for most of the variability in drowning incidence [2]. The top three provinces involved in our study, which were not the provinces with the largest populations, were all located within the Yangtze River Basin, which is known for its large number of various bodies of water. Consistent with other reports in China, most of the rescue incidents in our study occurred in fresh water and natural bodies of water $[26,27]$. Our results indicated that drowning location had a critical impact on the rescuers' survival, wherein lakes appeared to present lower risk than ponds, reservoirs and wells. Possible explanations for this location difference could be multifactorial. The lakes, whether artificial or natural, attract sightseers; therefore, multiple witnesses are typically available to perform rescue in a collaborative way. In contrast, ponds, reservoirs and wells in China often have steep and slippery water edges with considerable depth, resulting in lengthier stays in the water, along with greater difficulties for rescuers, all of which lead to detrimental outcomes in general [28]. A study conducted by Moran [29] also revealed that it was difficult for persons to exit deep water with variable edges. We further found that age was associated with the drowning location [2]; i.e., ponds were particularly high-risk places for children. However, children as PDVs also seem particularly likely to be associated with rescuer fatality [16], although the reason for this is unclear. Possible explanations could be that children are incapable of providing good cooperation to the rescuers, and that their rescuer was likely to be a peer.

Rescue efforts in hazardous conditions were often highly challenging, especially when additional rescuers or tools were not readily available [18, 28]. Pearn et al. indicated that $50 \%$ of rescuers in rescuer-who-drowns incidents were not familiar with the particular body of water and its hazards [14]. Therefore, drowning location would be a key variable in drowning prevention for both PDVs [2] and rescuers. Good understanding of the water environment before rescue should be strongly emphasized, and plans to effectively implement rescue operations in likely drowning environments need to be in place. Additionally, placement of isolation fencing and simple life-saving instruments in open water areas presumed to pose a high drowning risk could not only prevent most of the drowning caused by falls [2] but also provide PDVs and rescuers with floatation objects to hold that would improve the chances of survival [30].

Although the causes of drowning among rescuers were complex, several preventive suggestions have been proposed $[16,17]$. A successful rescue is technically challenging $[18,19]$. Rescuers without prior rescue knowledge mostly blundered into dangers and encountered lifethreatening events, including death [17]. Our study showed that pulling PDVs directly in the water increased the likelihood of a drowning fatality for rescuers. This may be owing to the fact that rescuers standing in water are more likely to lose their balance and become entangled with PDVs; this typically occurs with a contact tow (a rescuer human chain) [31]. Other practices such as swimming to the victim have also been found to be dangerous [14, 15]. Therefore, direct personal contact in an aquatic environment is extremely dangerous for rescuers. It has been proposed that rescue attempts from land or boat be the top priority [32]. The employing of water-away and indirect contact (offering an object such as a pole, stick, rope or plank)-or even noncontact-was the secondary recommendation $[30,33$, 34]. In addition, some professional rescue tools, such as rescue buoys, lifejackets, boats and lifelines, have proven essential for successful aquatic lifesaving $[18,19]$. Unfortunately, few Chinese rescuers performed water rescues properly.

On-scene rescuers also assume the responsibility to perform on-site pre-hospital resuscitation after rescue [35]. It has been reported that almost $30 \%$ of PDVs who were rescued by bystanders needed cardiopulmonary resuscitation [15], which, if done properly, could effectively contribute to a positive outcome [36, 37]. Rates of onscene resuscitation provided by bystanders vary among studies $[15,36,38]$. A Dutch study showed that approximately $31.8 \%$ of victims received resuscitation aid from bystanders [15]. Similarly, Topjian et al. found that onethird to one-half of rescued children in their study had received bystander cardiopulmonary resuscitation [38]. A hospital-based prospective study in Japan reported that $92 \%$ of the patients transported to hospital because of drowning had been given pre-hospital resuscitation [39]. The rate of pre-hospital resuscitation among victims in China is lower than these figures, leaving substantial room for improvement. Therefore, educating the public in basic first aid skills could be an important step [30].

\section{Limitations}

Although the present study offers a valuable data source for exploring drowning rescue events because most of the key variable information was contained in the reports $[17,40-42]$, the media is likely to underestimate the number of cases because of selective reporting [41]. Therefore, it is impossible to provide population-based rates on either PDVs or rescuers, and without population data it is not possible to extrapolate this information to all drowning rescue attempts. The media articles also often lack information on potential confounds, such as characteristics of water flow, the distance from shore, alcohol consumption of the rescuers, life vest application, 
differences in estimated swimming capacity (e.g., weak, average or strong), relationship between victims and rescuers, whether victims were warned of the potential drowning peril, or how the call for help was made. Moreover, we could not rule out the possibility that rescued victims died later, because media reports typically reported on victims' deaths at the scene but lacked post-rescue follow-ups. Additionally, missing data was another unavoidable problem: in cases where the rescuers left immediately after the rescue action, or where many rescuers performed rescue simultaneously, it would be difficult for the media to collect information on each of the rescuers at the desired level of detail.

\section{Conclusions}

Despite the survival of most PDVs and their rescuers, drowning rescue incidents still constitute a large number of unwanted VRDIs. A victim's young age (e.g., being a child) increased the risk of the rescuer's death. In China, drowning locations influenced rescuers' survival, and most of the life-saving methods employed were dangerous for rescuers. Moreover, the subsequent rate of onscene resuscitation after a successful rescue was far from sufficient. Accordingly, the idea of rescuers' safety first and discouraging children from rescue should be proposed. The results suggest the necessity of promoting education and training for the public to develop basic skills for a successful rescue, such as risk evaluation, request for bystanders' support, preference for non-contact rescue strategies and skills of post-rescue resuscitation.

\section{Competing interests}

The authors declare that they have no competing interests.

\section{Authors' contributions}

ZYC was responsible for study protocol design and statistical analysis. ZYC, LH, LFD and CJP were in charge of searching for relevant reports and extracting information. LFD and CJP assisted in data cleaning. ZYC and JX drafted the manuscript. All authors reviewed drafts of the manuscript and consented to the submitted version. All authors read and approved the final manuscript.

\section{Authors' information}

Yinchao Zhu and Xia Jiang share first-authorship.

\section{Acknowledgements}

The authors thank Pengpeng Ye and Ziyang Yu for their generous contributions during revisions of this paper.

\footnotetext{
Author details

${ }^{1}$ Institute of Non-Communicable Disease Control and Prevention, Ningbo Municipal Center for Disease Control and Prevention, No. 237, Yongfeng Road, Haishu District, Ningbo, Zhejiang Province 315010, People's Republic of China. ${ }^{2}$ Cardiovascular Epidemiology Unit, Institute of Environmental Medicine, Karolinska Institutet, Solna, 17172 Stockholm, Sweden. ${ }^{3}$ Department of Public Health Surveillance \& Advisory Division, Zhejiang Province Center for Disease Control and Prevention, No.630, Xincheng Road, Binjiang District, Hangzhou, Zhejiang Province 310051, People's Republic of China.
}

Received: 8 July 2014 Accepted: 1 July 2015

Published online: 10 July 2015

\section{References}

1. van Beeck EF, Branche CM, Szpilman D, Modell JH, Bierens JJ. A new definition of drowning: towards documentation and prevention of a global public health problem. Bull World Health Organ. 2005;83(11):853-6. doi:/S0042-96862005001100015.

2. Weiss J. American Academy of Pediatrics Committee on Injury, Violence, and Poison Prevention. Prevention of drowning. Pediatrics. 2010;126(1):e253-62. doi:10.1542/peds.2010-1265.

3. Schilling UM, Bortolin M. Drowning. Minerva Anestesiol. 2012;78(1):69-77.

4. Soar J, Perkins GD, Abbas G, Alfonzo A, Barelli A, Bierens JJ, et al. European Resuscitation Council Guidelines for Resuscitation 2010 Section 8. Cardiac arrest in special circumstances: Electrolyte abnormalities, poisoning, drowning, accidental hypothermia, hyperthermia, asthma, anaphylaxis, cardiac surgery, trauma, pregnancy, electrocution. Resuscitation. 2010;81(10):1400-33. doi:10.1016/j.resuscitation.2010.08.015.

5. Hyder AA, Borse NN, Blum L, Khan R, El Arifeen S, Baqui AH. Childhood drowning in low- and middle-income countries: Urgent need for intervention trials. J Paediatr Child Health. 2008;44(4):221-7. doi:10.1111/ j.1440-1754.2007.01273.x.

6. Centers for Disease Control and Prevention. Drowning-United States, 2005-2009. MMWR Morb Mortal Wkly Rep. 2012;61(19):344-7.

7. Jagnoor J, Suraweera W, Keay L, Ivers RQ, Thakur J, Jha P, et al. Unintentional injury mortality in India, 2005: nationally representative mortality survey of 1.1 million homes. BMC Public Health. 2012;12:487. doi:10.1186/1471-2458-12-487.

8. World Health Organization. Violence and Injury Prevention and Disability. 2004. http://wwwwhoint/mediacentre/factsheets/fs347/en/. Accessed Feb 2004.

9. Lunetta P, Smith GS, Penttila A, Sajantila A. Unintentional drowning in Finland 1970-2000: a population-based study. Int J Epidemiol. 2004;33(5):1053-63. doi:10.1093/ije/dyh194.

10. Ahlm K, Saveman Bl, Bjornstig U. Drowning deaths in Sweden with emphasis on the presence of alcohol and drugs - a retrospective study, 1992-2009. BMC Public Health. 2013;13:216. doi:10.1186/1471-2458-13-216.

11. Armour-Marshall J, Wolfe I, Richardson E, Karanikolos M, McKee M. Childhood deaths from injuries: trends and inequalities in Europe. Eur J Public Health. 2012;22(1):61-5. doi:10.1093/eurpub/ckr004.

12. Prameprart M, Lim A, Tongkumchum P. Modeling unintentional drowning mortality rates in Thailand, 2000-2009. Asia Pac J Public Health. 2013. doi:10.1177/1010539513488796

13. Wang LJ, Hu N, Wan X, Zhou MG, Wang J. Status and trend of injury deaths among Chinese population, 1991-2005. Zhonghua Yu Fang Yi Xue Za Zhi. 2010;44(4):309-13.

14. Pearn JH, Franklin RC. The Impulse to Rescue": rescue altruism and the challenge of saving the rescuer. Int J Aquat Res Educ. 2012;6(4):325-35.

15. Venema AM, Groothoff JW, Bierens JJ. The role of bystanders during rescue and resuscitation of drowning victims. Resuscitation. 2010;81(4):434-9. doi:10.1016/j.resuscitation.2010.01.005.

16. Franklin RC, Pearn JH. Drowning for love: the aquatic victim-instead-of-rescuer syndrome: drowning fatalities involving those attempting to rescue a child. J Paediatr Child Health. 2011;47(1-2):44-7. doi:10.1111/j.1440-1754.2010.01889.x.

17. Turgut A, Turgut T. A study on rescuer drowning and multiple drowning incidents. J Safety Res. 2012;43(2):129-32. doi:10.1016/j.jsr.2012.05.001.

18. Brons R, Brewster C, Espino M, Goto R, Short A, Wright R, et al. Task Force on Rescue- Organisational Aspects: Rescue Planning, Trainning and preparation. In: Brons R, Brewster C, editors. Handbook on Drowning Prevention, Rescue, Treatment. Heidelberg: Springer Verlag; 2006. p. 135-87.

19. Brewster C, Brons R, Zwitser E, Sims B, Fenner P, Griffiths T, et al. Task Force on Rescue- Rescue Techniques. In: Brewster C, Brons R, editors. Handbook on Drowning Prevention, Rescue, Treatment. Heidelberg: Springer Verlag; 2006. p. 193-308.

20. Castan J, Wirtz S, Moecke H, Schmidbauer W, Bubser F, Kerner T. First therapy of drowning accident. Anasthesiol Intensivmed Notfallmed Schmerzther. 2009;44(7-8):486-93. doi:10.1055/s-0029-1237101.

21. International Lifesaving Federation[ILS]. World Drowning Report(2007 Edition). Leuven:lls. 2007.

22. Geier CF. Adolescent cognitive control and reward processing: implications for risk taking and substance use. Horm Behav. 2013;64(2):333-42. doi:10.1016/j.yhbeh.2013.02.008.

23. Barton BK, Ulrich T, Lyday B. The roles of gender, age and cognitive development in children's pedestrian route selection. Child Care Health Dev. 2012;38(2):280-6. doi:10.1111/j.1365-2214.2010.01202.x. 
24. Gulliver P, Begg D. Usual water-related behaviour and 'near-drowning' incidents in young adults. Aust N Z J Public Health. 2005;29(3):238-43.

25. Pearn JH, Gardner-Medwin D. An Anzac's childhood: John Simpson Kirkpatrick (1892-1915). Med J Aust. 2003;178(8):400-2.

26. Ma WJ, Nie SP, Xu HF, Xu YJ, Song XL, Guo QZ, et al. An analysis of risk factors of non-fatal drowning among children in rural areas of Guangdong Province, China: a case-control study. BMC Public Health. 2010;10:156. doi:10.1186/1471-2458-10-156.

27. Quanx N, Li Y. Analysis on drowning among children in rural areas of Guangxi province. Chin J Public Health. 2006;22(9):1043-4.

28. Petridou E, Klimentopoulou A. Risk Factors for Drowning. In: Branche C, Van Beeck E, editors. Handbook on Drowning Prevention, Rescue, Treatment. Heidelberg: Springer Verlag; 2006. p. 63-9.

29. Moran K. Getting Out of the Water: How Hard Can That Be? IJARE. 2014;8(4):321-37 http://dx.doi.org/10.1123/ijare.2014-0054.

30. Pearn JH, Franklin RC. "Flingin the Squaler" Lifeline Rescues for Drowning Prevention. Int J Aquat Res Educ. 2009;3:315-21.

31. Ding WT. Enlightment from the Hero Group Reported on the 24, Oct. Young Journalists. 2009;35:29-30.

32. Connolly J. Suicide by Drowning in Ireland. Irish Life Saving Foundation, http://lifesavingfoundationie/pages/publications/internal/ suicidebydrowninirewwscpdf. Accessed 12 Jun 2011.

33. Deutsche Lebens-Rettungs-Gesellschaft [DLRG]. Teilnehmerbroschüre Rettungsschwimmen [in English: Participant Brochure of Lifesaving in Water]. Bad Nenndorf: DLRG. 2005a.

34. Deutsche Lebens-Rettungs-Gesellschaft [DLRG]. Handbuch Rettungsschwimmen [in English: Handbook of Lifesaving]. Bad Nenndorf: DLRG. 2005b.

35. Pepe P, Bierens J, Wigginton J, Mann D, Persse D, Sirbaugh P, et al Resuscitation. In: Pepe P, Bierens J, editors. Handbook on Drowning Prevention, Rescue, Treatment. Heidelberg: Springer Verlag; 2006. p. 312-77.

36. Mosayebi Z, Movahedian AH, Mousavi GA. Drowning in children in Iran: outcomes and prognostic factors. Med J Malaysia. 2011;66(3):187-90.

37. Langley J. Review of Literature on Available Strategies for Drowning Prevention. In: Branche C, Van Beeck E, editors. Handbook on Drowning Prevention, Rescue, Treatment. Heidelberg: Springer Verlag; 2006. p. 70-3.

38. Topjian AA, Berg RA. Pediatric out-of-hospital cardiac arrest. Circulation. 2012;125(19):2374-8. doi:10.1161/CIRCULATIONAHA.111.071472.

39. Nitta M, Iwami T, Kitamura T, Nadkarni VM, Berg RA, Shimizu N, et al. Agespecific differences in outcomes after out-of-hospital cardiac arrests. Pediatrics. 2011;128(4):e812-20. doi:10.1542/peds.2010-3886.

40. Barss P, Subait OM, Ali MH, Grivna M. Drowning in a high-income developing country in the Middle East: newspapers as an essential resource for injury surveillance. J Sci Med Sport. 2009;12(1):164-70. doi:10.1016/j.jsams.2007.08.016

41. Baullinger J, Quan L, Bennett E, Cummings P, Williams K. Use of Washington State newspapers for submersion injury surveillance. Inj Prev. 2001;7(4):339-42.

42. Ghaffar A, Hyder AA, Bishai D. Newspaper reports as a source for injury data in developing countries. Health Policy Plan. 2001;16(3):322-5.

\section{Submit your next manuscript to BioMed Central and take full advantage of:}

- Convenient online submission

- Thorough peer review

- No space constraints or color figure charges

- Immediate publication on acceptance

- Inclusion in PubMed, CAS, Scopus and Google Scholar

- Research which is freely available for redistribution

Submit your manuscript at www.biomedcentral.com/submit 